\title{
The impact of COVID-19 on REl fellowship educational experience
}

\author{
Luwam Ghidei $^{1}$ (D) Alexandra Gannon ${ }^{1} \cdot$ Amy Schutt $^{1}$ \\ Received: 14 December 2020 / Accepted: 18 March 2021 / Published online: 1 April 2021 \\ (C) The Author(s), under exclusive licence to Springer Science+Business Media, LLC, part of Springer Nature 2021
}

\begin{abstract}
Purpose To assess perceived deficiencies of reproductive endocrinology and infertility (REI) fellow education due to changes in care secondary to COVID- 19 .

Methods This is a cross-sectional study performed in an academic setting. A survey was generated and administered to REI fellows and attendings practicing in programs across the United States. Descriptive statistics were used to quantify results regarding clinical volume, academic responsibilities, clinical safety, and fellowship education.

Results The survey response rate was $23 \%$. Eighty-four percent of respondents self-identified as fellows, and $16 \%$ identified as program directors or other REI academic instructors. Overall, the survey responses confirmed that the COVID-19 pandemic tremendously affected clinical volume, with $91 \%$ of participants reporting their clinical volume decreased by at least half. Although $67 \%$ of attendings believed that the changes related to COVID-19 have or will have significantly affected the clinical skills of fellows, $66 \%$ of fellows did not believe that their clinical training had been significantly impacted. Sixty-seven percent of fellows and $78 \%$ of attendings do not believe that changes related to COVID-19 will affect the ability of fellows to practice independently.

Conclusion Even though most attendings surveyed believed that the changes related to COVID-19 would affect the clinical skills of fellows, the cessation of clinical and research activities was short-lived, likely tempering the overall effect on clinical training. Overall, most respondents did not believe that the pandemic significantly affected fellow education.
\end{abstract}

Keywords SARS-CoV-2 $\cdot$ Covid-19 $\cdot$ Coronavirus $\cdot$ Education $\cdot$ Fellowship

\section{Introduction}

In January 2020, the first known infection by the coronavirus Sars-CoV-2 appeared in the United States [1,2]. Since that time, the United States has become the world leader in the number of people diagnosed with COVID-19. At the time of writing this manuscript, the number of COVID-19 cases in the United States has surpassed 7 million [3], with daily case counts surpassing 100,000 [4]. On March 14, 2020, as COVID-19 cases steadily rose in European countries, the European Society of Human Reproduction and Embryology (ESHRE) released a statement recommending that all fertility patients considering or planning treatment, even if they do not meet the diagnostic criteria for Sars-CoV-2 infection, should avoid becoming pregnant at this time [5]. Shortly after, on

Luwam Ghidei

lghidei@gmail.com

1 Department of Obstetrics and Gynecology, Baylor College of Medicine, 6651 Main Street, 10th floor, TX 77030 Houston, USA
March 17, 2020, the American Society of Reproductive Medicine (ASRM) released recommendations to suspend initiation of new treatment cycles, consider canceling embryo transfers, suspend elective surgeries, and minimize in-person interaction by utilization of telemedicine [6]. The result of these recommendations was the temporary closure of multiple fertility clinics across the United States.

In the academic setting, canceled treatment cycles and surgeries led to a sharp decline in patient care, reducing tangible learning opportunities for reproductive endocrinology and infertility (REI) fellows. On April 24, 2020, ASRM released an update to their recommendations which supported resuming care in individual clinics based on individual assessment of program location disease state and transmission risk [7]. However, despite a gradual reopening, many clinics across the country continued to experience a relatively lower volume of patients. The decrease in patient volume has been a shared concern among several medical specialties, calling into question fellow preparedness and readiness for independent practice $[8,9]$. While the effects of the COVID-19 pandemic on REI fellowships remain largely unknown, there is concern that fellows will graduate with fewer procedural skills, less research experience, and less experience 
with cycle management than their historical counterparts. Identifying this gap in knowledge is of utmost importance in order to ensure adequate fellow preparedness and education. The aim of this study is to assess perceived deficiencies of REI fellow education due to changes in care secondary to COVID-19. Specifically, we want to assess any potential effects of decreased patient volume, interruptions in formalized didactics, decreased procedural volume, and changes in fellow well-being during the first wave of the COVID-19 pandemic.

\section{Impact of COVID-19 survey}

The purpose of this survey is to learn more about the effects of Covid-19 on REl fellowships. Thank you in advance for taking time to inform us of your experience

\begin{tabular}{ll}
\hline What is your title? & ○ Fellow $\bigcirc$ Assistant Program Director \\
& PD) \\
& \\
\hline What was your level of fellowship for the 2019-2020 & $\bigcirc$ 1st year fellow $\bigcirc$ 2nd year fellow \\
term? & $\bigcirc$ 3rd year fellow $\bigcirc$ Recent graduate \\
& $\bigcirc$ Incoming fellow \\
\hline In your opinion, how significantly was your city & $\bigcirc$ Less than the average US city \\
affected by Covid-19? & $\bigcirc$ Similar to the average US city \\
& $\bigcirc$ More than the average US city \\
& $\bigcirc$ My city was considered a Covid-19 hot spot
\end{tabular}

\begin{tabular}{|c|c|c|c|c|c|c|c|c|}
\hline \multicolumn{9}{|c|}{ During the height of the Covid-19 pandemic: } \\
\hline & $100 \%$ less & $75 \%$ less & $50 \%$ less & $25 \%$ less & $\begin{array}{c}\text { No } \\
\text { change }\end{array}$ & $25 \%$ more & $\begin{array}{l}50 \% \\
\text { more }\end{array}$ & $75 \%$ more \\
\hline $\begin{array}{l}\text { How significantly did your clinic's } \\
\text { patient volume change? }\end{array}$ & $\bigcirc$ & $\bigcirc$ & $\bigcirc$ & $\bigcirc$ & $\bigcirc$ & $\bigcirc$ & $\bigcirc$ & $\bigcirc$ \\
\hline $\begin{array}{l}\text { How significantly did the hours } \\
\text { you spent performing clinical } \\
\text { work change? }\end{array}$ & $\bigcirc$ & $\bigcirc$ & $\bigcirc$ & $\bigcirc$ & $\bigcirc$ & O & $\bigcirc$ & $\bigcirc$ \\
\hline $\begin{array}{l}\text { How significantly did the hours } \\
\text { you spent performing research } \\
\text { change? }\end{array}$ & 0 & $\bigcirc$ & $\bigcirc$ & $\bigcirc$ & $\bigcirc$ & O & $\bigcirc$ & $\bigcirc$ \\
\hline
\end{tabular}

\begin{tabular}{ll}
\hline How significantly did your research experience related & $\bigcirc$ Could not perform research \\
to your thesis change? & O I could perform research but my research was \\
limited & $\bigcirc$ I was able to perform more research than before \\
& O Not applicable
\end{tabular}

\begin{tabular}{ll}
\hline How significantly did your total research experience & I could not perform research \\
change? & O I could perform research but my research was \\
& limited \\
& $\bigcirc$ I was able to perform more research than before \\
& Not applicable
\end{tabular}

\begin{tabular}{ll}
\hline $\begin{array}{l}\text { Were there interruptions in formal didactics due to } \\
\text { Covid-19? }\end{array}$ & $\bigcirc$ Yes $\bigcirc$ No \\
\hline $\begin{array}{ll}\text { How did the quality of your program's formal didactics } & \bigcirc \text { Diminished } \\
\text { change? } & \bigcirc \text { No change } \\
& \bigcirc \text { Enhanced }\end{array}$
\end{tabular}

Fig. 1 Impact of COVID-19 survey 


\begin{tabular}{|c|c|c|c|c|c|c|c|c|}
\hline \multicolumn{9}{|c|}{ During Covid-19, how did the amount of the following procedures performed in your practice } \\
\hline & $\begin{array}{l}\text { Did not } \\
\text { perform } \\
\text { any of } \\
\text { these } \\
\text { cases }\end{array}$ & $75 \%$ less & $50 \%$ less & $25 \%$ less & $\begin{array}{c}\text { No } \\
\text { change }\end{array}$ & $25 \%$ more & $\begin{array}{l}50 \% \\
\text { more }\end{array}$ & $75 \%$ more \\
\hline Transvaginal aspiration & $\bigcirc$ & $\bigcirc$ & $\bigcirc$ & $\bigcirc$ & $\bigcirc$ & $\bigcirc$ & $\bigcirc$ & $\bigcirc$ \\
\hline Frozen embryo transfer & $\bigcirc$ & $\bigcirc$ & $\bigcirc$ & $\bigcirc$ & $\bigcirc$ & $\bigcirc$ & $\bigcirc$ & O \\
\hline Intrauterine insemination & $\bigcirc$ & $\bigcirc$ & $\bigcirc$ & $\bigcirc$ & $\bigcirc$ & $\bigcirc$ & $\bigcirc$ & 0 \\
\hline Mock embryo transfer & O & O & $\bigcirc$ & 0 & $\bigcirc$ & $\bigcirc$ & $\bigcirc$ & 0 \\
\hline $\begin{array}{l}\text { Saline-infusion } \\
\text { sonohysterography }\end{array}$ & 0 & $\bigcirc$ & $\bigcirc$ & $\bigcirc$ & $\bigcirc$ & $\bigcirc$ & $\bigcirc$ & $\bigcirc$ \\
\hline Hysterosalpingogram & $\bigcirc$ & O & 0 & 0 & $\bigcirc$ & $\bigcirc$ & 0 & 0 \\
\hline Hysteroscopy & $\bigcirc$ & $\bigcirc$ & $\bigcirc$ & $\bigcirc$ & $\bigcirc$ & $\bigcirc$ & O & $\bigcirc$ \\
\hline Laparoscopy & $\bigcirc$ & $\bigcirc$ & $\bigcirc$ & $\bigcirc$ & $\bigcirc$ & $\bigcirc$ & $\bigcirc$ & $\bigcirc$ \\
\hline Robotic surgery & $\bigcirc$ & 0 & $\bigcirc$ & $\bigcirc$ & $\bigcirc$ & 0 & 0 & 0 \\
\hline Laparotomy & $\bigcirc$ & $\bigcirc$ & $\bigcirc$ & $\bigcirc$ & $\bigcirc$ & $\bigcirc$ & $\bigcirc$ & O \\
\hline & $100 \%$ less & $75 \%$ less & $50 \%$ less & $25 \%$ less & $\begin{array}{c}\text { No } \\
\text { change }\end{array}$ & $25 \%$ more & $\begin{array}{l}50 \% \\
\text { more }\end{array}$ & $75 \%$ more \\
\hline
\end{tabular}

During the Covid-19 pandemic, how did the amount of IVF cycles you reviewed change?

\begin{tabular}{lcccccc}
\hline & $\begin{array}{c}\text { Very } \\
\text { unsatisfied }\end{array}$ & Unsatisfied & Neutral & Satisfied & Very satisfied & not applicable \\
$\begin{array}{l}\text { Overall, how was your } \\
\text { experience with telemedicine? }\end{array}$ & 0 & 0 & 0 & 0 & 0 & $\bigcirc$
\end{tabular}

Please elaborate on your telemedicine experience (technical issues, educational experience, ease of use, convenience)

\begin{tabular}{|c|c|}
\hline Have you been tested for Covid-19? & $\bigcirc$ Yes $\bigcirc$ No \\
\hline Did you test positive for Covid-19? & $\bigcirc$ Yes $\bigcirc$ No \\
\hline $\begin{array}{l}\text { Do you know any co-worker who tested positive for } \\
\text { Covid-19? }\end{array}$ & $\bigcirc$ Yes $\bigcirc$ No \\
\hline Who tested positive for Covid-19? & $\begin{array}{l}\bigcirc \text { Fellow } \bigcirc \text { Attending } \\
\text { Nurse } \bigcirc \text { Medical assistant } \\
\text { Sonographer } \bigcirc \text { Administrator } \\
\text { Other }\end{array}$ \\
\hline
\end{tabular}

Fig. 1 (continued)

\section{Materials and methods}

Areas of focus were identified and agreed upon by the authors. A survey was generated to capture the effects of the first wave of the pandemic between March 15th and June 15th, 2020, using the REDCap (Research Electronic Data Capture) survey platform [10-12]. REDCap is a secure, web-based software platform designed to support data capture for research studies.

Inclusion criteria for this study included all current REI fellows, REI fellows graduating in 2020, and REI faculty including program directors. Subjects were contacted by email requesting their response via survey. Participants who completed the survey from August 25th to September 9th, 2020, were included. Exclusion criteria included subjects who did not complete survey or only partially completed the survey in addition to fellows who were not matriculated at the time of this survey. Prior to starting the survey, subjects were informed that participation was voluntary. The results of the survey were maintained on REDCap secure web platform. Descriptive statistics were used to describe the cohort. This 
Please answer the next 6 questions on a scale of 1 to 10, with 1 being "not at all" and 10 being

"very":

$\begin{array}{rllllllllll}1 & 2 & 3 & 4 & 5 & 6 & 7 & 8 & 9 & 10 & \begin{array}{r}\text { Does } \\ \text { not }\end{array}\end{array}$

apply

to me

When clinic re-opened, how much did you agree with the decision to re-start fertility

treatments at your institution

How safe did you feel once you were back in clinic?

How would you describe your fear of illness?

How would you rate communication between program leaders and fellows regarding changes related to Covid-19?

How significantly has the changes related to Covid-19 affected clinical skills of fellows?

How significantly has the changes related to Covid-19 affected the ability of fellows to practice independently

The next questions are related to wellness. Please answer questions on a scale of 1 to 10, with 1 being "not at all" and 10 being "very":

$$
\begin{aligned}
& \text { Strongly } \\
& \text { disagree }
\end{aligned}
$$

The changes related to Covid-19 have positively affected my sleep regimen

The changes related to Covid-19 have positively affected my exercise routine

The changes related to Covid-19 have positively affected my overall happiness

The changes related to Covid-19 have positively affected my overall wellness

Fig. 1 (continued)

study was approved by the Baylor College of Medicine Institutional Review Board (IRB). A copy of the survey has been included as Fig. 1.

\section{Results}

The survey response rate was $23 \%$ (54 out of 235) (Fig. 2). Eighty-four percent of respondents self-identified as fellows, and $16 \%$ identified as program directors or other REI academic instructors. Of the fellows, $41 \%$ were first year, $38 \%$ second year, $18 \%$ third year, and $2 \%$ recently graduating fellows. Respondents who were incoming fellows $(<1 \%)$ were excluded from the analysis. Most respondents were significantly affected by the COVID-19 pandemic, with $39 \%$ considering their city a "COVID-19 hot spot." In fact, $87 \%$ described their city affected by COVID-19 in a manner similar to the average US city or worse.

Overall, the survey responses confirmed that the COVID19 pandemic tremendously affected clinical volume, with 
$91 \%$ of participants reporting their clinical volume decreased by at least half. Specifically, surgical and procedural volumes were notably affected. Given the unknown reproductive risks of COVID-19 on pregnant women and fetuses in addition to the significant risk of exposure for clinical staff, many precautions were taken to minimize transmission and exposure. Transvaginal oocyte aspirations (TVAs) were substantially reduced if not completely paused across the nation, with 94\% respondents performing fewer TVAs and half not performing any at all. The amount of frozen embryo transfers and intrauterine inseminations performed were also significantly reduced for $94 \%$ and $93 \%$ of respondents, respectively. Diagnostic procedures such as saline-infused sonohysterograms (SISs) and hysterosalpingograms (HSGs) were affected as well. When asked if they performed at least $25 \%$ fewer SISs and HSGs during the COVID-19 pandemic, more than $83 \%$ of respondents agreed. Moreover, $52 \%$ did not perform any HSGs at all. Surgical cases were practically halted for many clinicians: 93\% reported performing less laparoscopy, and $48 \%$ ceased laparotomy all together. This trend was similar for hysteroscopy (HSC) as well.

Ninety-one percent of fellows reported reviewing fewer in vitro fertilization (IVF) stimulation cycles, while the remaining 9\% did not report any change, which could represent responses from non-clinical fellows. None of the respondents were unsatisfied with telemedicine. In fact, $64 \%$ of fellows and $78 \%$ of attendings were satisfied with their telemedicine experience.
Regarding other academic responsibilities, $64 \%$ of overall respondents stated that research was limited or they could not perform research at all. The COVID-19 pandemic significantly affected thesis-related research for $63 \%$ of fellows. Interestingly, $74 \%$ reported that didactics were not affected during the pandemic, perhaps due to the transition of didactics to virtual platforms. In fact, $25 \%$ of respondents stated didactics were enhanced due to the pandemic.

Although $67 \%$ of attendings believe the changes related to COVID-19 have or will have significantly affected the clinical skills of fellows, $66 \%$ of fellows did not believe their clinical training had been significantly impacted (Fisher's exact test, OR 3.76 ; $p$-value 0.13 ) Sixty-seven percent of fellows and $78 \%$ of attendings did not believe changes related to COVID-19 have affected the ability of fellows to practice independently.

At the time of survey administration, $64 \%$ of overall respondents reported being tested for COVID-19 at some point. At least 3 fellows and 2 attendings tested positive, and $58 \%$ of respondents knew of a coworker who tested positive. Even though $55 \%$ of all respondents described moderate or high fear of illness, $89 \%$ of respondents agreed with the decision to restart fertility treatments at their institution ( $80 \%$ of fellows and $89 \%$ of attendings) (Fig. 3). Once back in clinic, $91 \%$ of overall respondents reported feeling safe. However, $27 \%$ of fellows felt that communication regarding administrative changes related to COVID-19 were suboptimal.

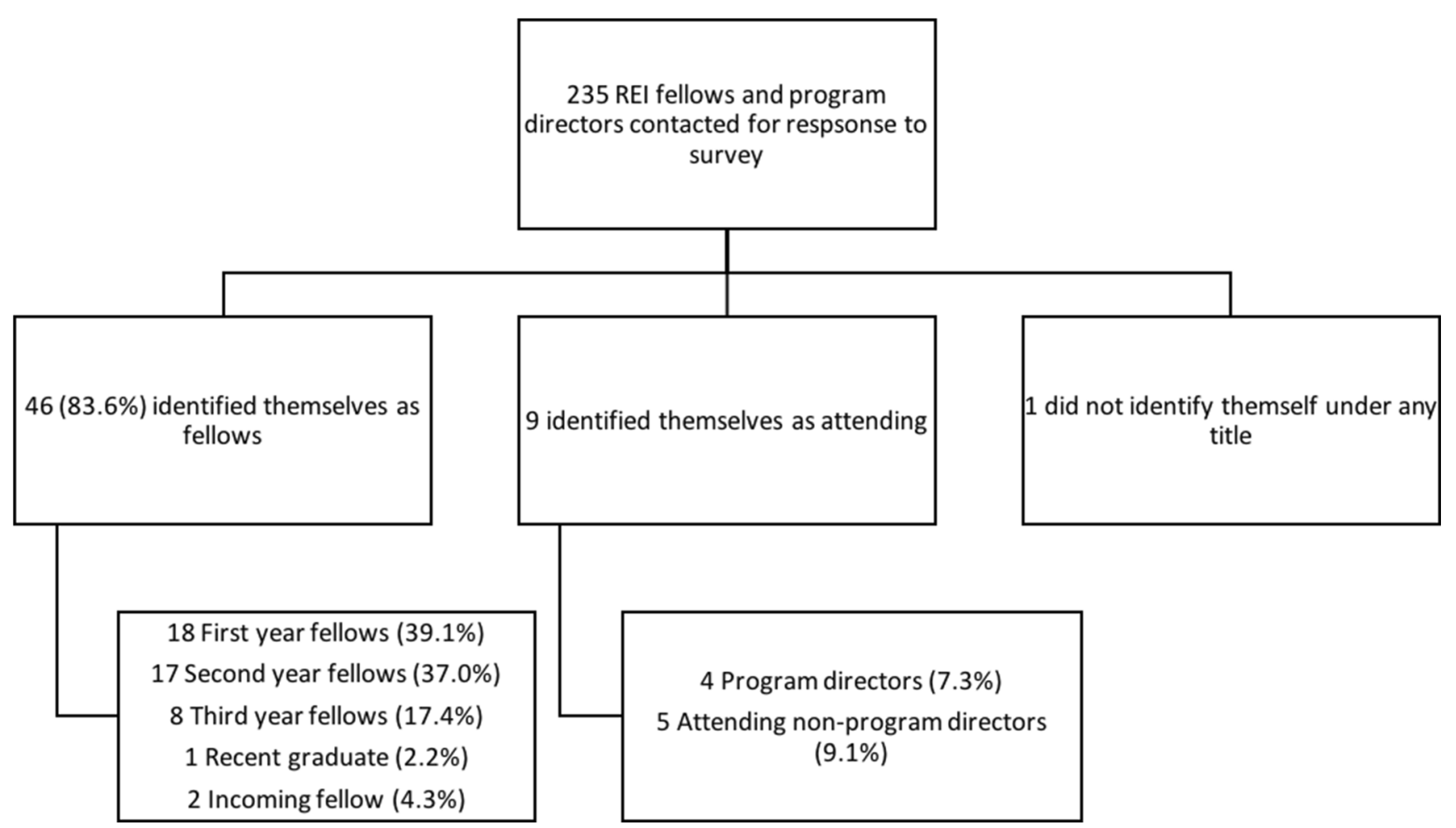

Fig. 2 Flowchart of patient selection 
Fig. 3 Participant response to decision to restart fertility treatments

\section{From a scale of 1 to 10 , how much did you agree with the decision to restart treatments at your institution?}

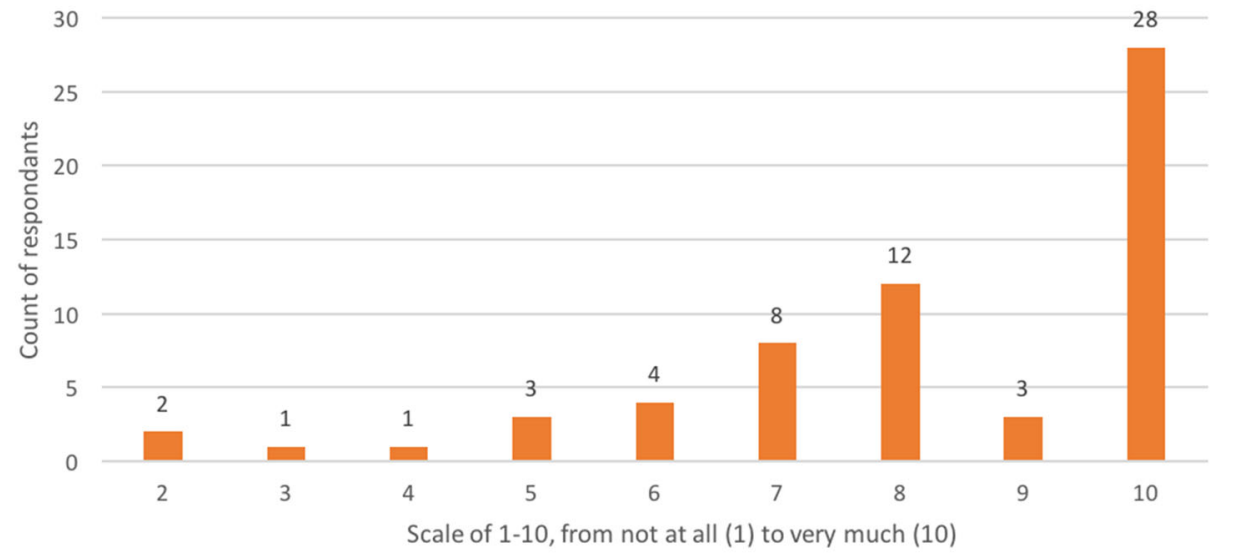

\section{Discussion}

The results of this survey illustrate some of the ways that the first wave of the COVID-19 pandemic has affected the clinical atmosphere for REI clinicians, patients, clinical staff, and greater hospital systems. Patient visits, surgeries, clinical tests, reproductive procedures, and treatments were canceled or postponed across the nation during the height of the pandemic as hospital systems braced for shortages of resources and attempted to mitigate largely unknown risks of COVID-19. Along with diminished clinical volume, most fellows were limited in the amount of research they could conduct. Fortunately for many programs, formal didactic sessions did not appear to be negatively impacted during this time and may have even been enhanced.

Eight months into the pandemic, there were over 100,000 daily new confirmed cases of COVID-19 in the USA [4].This represents quite an acceleration of cases from what may have been predicted at the start of the pandemic, when there were 36,741 new cases confirmed on April 24th. Guidance from the ASRM, in particular, the ASRM task force, was instrumental in providing resources and recommendations for clinics during the early days of the pandemic. As preventative measures, COVID-19 testing and protocol guidelines were implemented, and REI clinics and clinicians resumed most clinical activity including reproductive surgeries and assisted reproductive technology treatments.

Even though most attendings surveyed believed that the changes related to COVID-19 would affect the clinical skills of fellows, the cessation of clinical and research activities was short-lived, likely tempering the overall effect on clinical training. Overall, most respondents did not believe the pandemic has significantly affected fellow education. The results of this survey suggest that in the future, we should leverage virtual didactics to supplement loss of learning in the clinic. Virtual platforms can also be utilized to review cycle management and discuss treatment plans for learning purposes. Programs should increase simulation if possible, especially using modules such as the ASRM embryo transfer course. Furthermore, programs and fellows can take advantage of the numerous ASRM modules and grand rounds to enhance fellow education. Given that many respondents signified limited ability to perform their research, it may be prudent to encourage and prioritize clinical research projects in the case of future disruptions to patient care and recruitment.

Limitations of this survey include a relatively low response rate. Most respondents were first and second year fellows, thus limiting the sub-analysis of third year fellows, program directors, and instructors. Furthermore, we may have oversampled respondents from "COVID-19 hot spots" and purely academic settings, leading to selection bias. Seeing that we are still in the midst of the pandemic, we could not specifically define the time frame for the "height" of the pandemic for this survey. Additionally, the rebound of clinical volumes after restrictions in many regions were lifted during the summer of 2020 was not captured in this cross-sectional survey.

\section{Conclusion}

According to the American Medical Association, the pandemic has affected both training and the career opportunities for physicians entering the job market. Medical schools across the nation have revised curricula and adopted robust changes to support the public health response [9]. Many residents and fellows were redeployed to ICU wards to help battle the pandemic, potentially impacting clinical training and applications for subspecialization. Additionally, trainees may have missed 
opportunities to acquire critical surgical skills once elective surgeries were canceled. Fortunately, the 3-year REI fellowship training model has the capability to mitigate these limitations caused by the pandemic.

In this survey, REI fellows and attendings alike reported significantly lower procedure volume, less research time, and fewer IVF cycle management reviews during the early phase of the COVID-19 pandemic. However, those limitations seem to be temporary with the swift implementation of practice guidelines and safe measures. Moving forward, it will be prudent for programs to assess the individual effect on their fellows and perhaps take advantage of more simulation and/or re-allocation of clinical and research rotations.

\section{References}

1. Holshue ML, DeBolt C, Lindquist S, Lofy KH, Wiesman J, Bruce $\mathrm{H}$, et al. First case of 2019 novel coronavirus in the United States. N Engl J Med. 2020;382(10):929-36.

2. Lucey CR, Johnston SC. The transformational effects of COVID19 on medical education. JAMA. 2020;324(11):1033-4. https:// doi.org/10.1001/jama.2020.14136.

3. Covid-19 dashboard by the Center Systems Science and Engineering (CSSE) at Johns Hopkins University. 2020 [cited 2020 September 20]; Available from: https://map.html/map.html. Accessed 20 Sept 2020
4. Centers for disease control and prevention, C.-R.C.-C.S.P.D.A., summary, and limitations (version date: October 31, 2020)

5. Coronavirus Covid-19: ESHRE statement on pregnancy and conception. 2020

6. American Society for Reproductive Medicine (2020) (ASRM) patient management and clinical recommendations during the Coronavirus (Covid-19) pandemic Update \#1

7. American Society for Reproductive Medicine (2020) (ASRM) patient management and clinical recommendations during the Coronavirus (Covid-19) pandemic Update \#3

8. Hagedorn JM et al. (2020) Impact of COVID-19 on pain medicine fellowship training. Regional Anesthesia \& Pain Medicine: p. rapm-2020-101534

9. Gupta T, et al. Impact of the COVID-19 pandemic on interventional cardiology fellowship training in the New York metropolitan area: A perspective from the United States epicenter. Catheter Cardiovase Interv. 2020.

10. "COVID-19 Data Repository by the Center for Systems Science and Engineering (CSSE) at Johns Hopkins University" URL: https://github.com/CSSEGISandData/COVID-19. Accessed 20 Sept 2020

11. Harris P, Taylor R, Minor BL, Elliott V, Fernandez M, O’Neal L, et al. The REDCap consortium: building an international community of software partners. J Biomed Inform.

12. Harris P, Taylor R, Thielke R, Payne J, Gonzalez N, Conde JG. Research electronic data capture (REDCap) - A metadata-driven methodology and workflow process for providing translational research informatics support. J Biomed Inform. 2009;42(2):5.

Publisher's note Springer Nature remains neutral with regard to jurisdictional claims in published maps and institutional affiliations. 